\title{
Urgência e Emergência: os conceitos frente às normas administrativas e legais e suas implicações na clínica médica
}

\section{Urgency and Emergency. The concepts in the administrative and legal regulations and their impact on the clinical medicine}

\author{
Humberto Mena1, Gabriel V. M. Piacsek ${ }^{2}$, Márcia Vieira da Motta ${ }^{3}$
}

DOI: http://dx.doi.org/10.11606/issn.2317-2770.v22i2p81-94

\begin{abstract}
Mena H, Piacsek GVM, Motta MV. Urgência e Emergência: os conceitos frente às normas administrativas e legais e suas implicações na clínica médica. Saúde, Ética \& Justiça. 2017;22(2):81-94.

RESUMO: As situações de emergência e de urgência apresentam conceitos distintos para aqueles que prestam o serviço médico, para quem o recebe, para quem paga pelos serviços e para aqueles que legislam sobre a matéria. Distinções conceituais encontradas na legislação de planos de saúde e nas normativas administrativas demandam que o profissional da saúde, em seus pedidos de exames, procedimentos e internações, descreva a situação clínica de forma extensiva para não imputar ao paciente o ônus de comprovar a necessidade de pronto atendimento junto aos prestadores de serviço e, eventualmente, na Justiça. Isso porque a Lei no 9.656 restringiu o conceito de urgência para situações de acidentes pessoais e complicações gestacionais e excluiu das emergências as situações de sofrimento intenso. Ampliou, contudo, o conceito de emergências, que abarca cobertura de casos em que há risco de ocorrerem lesões irreparáveis para o paciente. Conferiu definição extensiva para tratamento imediato, que passou a poder ser oferecido em até 24 horas. A jurisprudência estudada indicou a importância dos documentos médico-legais na caracterização dos quadros clínicos e garantia dos direitos frente aos contratos de planos de saúde.
\end{abstract}

DESCRITORES: Planos de Pré-Pagamento em Saúde; Emergências; Atos Administrativos; Assistência à Saúde; Direito Sanitário.

\footnotetext{
1. Departamento de Medicina Legal, Ética Médica, Medicina Social e do Trabalho da Faculdade de Medicina da USP. humberto. mena65@gmail.com

2. St. Olaf College. piacse1@stolaf.edu

3. Faculdade de Medicina da Universidade de São Paulo. Departamento de Medicina Legal, Ética Médica, Medicina Social e do Trabalho da Faculdade de Medicina da USP. marcia.motta@gmail.com

Endereço para correspondência: Faculdade de Medicina da Universidade de São Paulo. Departamento de Medicina Legal, Ética Médica, Medicina Social e do Trabalho da Faculdade de Medicina da USP. Rua Teodoro Sampaio, 115, São Paulo, SP. CEP 05405-000.
} 


\section{INTRODUÇÃO}

$\mathbf{S}$ ituações de emergência e de urgência são normalmente reconhecidas como aquelas em que a pronta atenção médica se faz necessária, muito embora haja diferenças conceituais para quem presta o serviço médico, para quem o recebe, para quem o financia e para quem legisla sobre a matéria. Assim, não é difícil imaginar que essas discrepâncias possam ter implicações fatais aos destinatários da atenção médica, dada a infinidade de condições que separam os casos emergenciais dos urgentes e, ainda, dos eletivos.

No Brasil, o Conselho Federal de Medicina $(\mathrm{CFM})^{1}$ estipulou definição precisa para os termos, tendo o Ministério da Saúde ${ }^{2}$ adotado o mesmo entendimento na organização das Redes de Atenção à Saúde ${ }^{3,4}$ e na Política Nacional de Atenção às Urgências ${ }^{5,6}$ do Sistema Único de Saúde (SUS) 7 , um dos maiores sistemas públicos de saúde do mundo, que tem como objetivo garantir o acesso integral, universal e gratuito à saúde para toda a população brasileira ${ }^{8}$.

A Constituição garante que os serviços de saúde podem ser executados por terceiros, sendo livres à iniciativa privada de forma complementar ou suplementar ao SUS, respeitadas as diretrizes dele ${ }^{8}$. A saúde suplementar, centrada na operação de planos privados de assistência à saúde sob regulação do Poder Público, foi regulamentada em 1998, pela Lei $\mathrm{n}^{\circ} 9.656^{9}$. Esta lei estabeleceu parâmetros para a cobertura dos procedimentos médicos e, dentre eles, identificou de forma restritiva o conceito de urgência e ampliou o de emergência; inovando sobre a matéria em termos legais, manteve apenas o entendimento de que haveria perigo de morte nos casos emergenciais, conforme prescrito pelo $\mathrm{CFM}^{1}$

Como consequência, quando um médico prescreve urgência no atendimento frente aos parâmetros clínicos do caso ("ocorrência imprevista de agravo à saúde com ou sem risco potencial de vida, cujo portador necessita de assistência médica imediata") ${ }^{1}$, se este não se enquadrar na definição de urgência da Lei n ${ }^{\circ} 9.656$, ou seja, de situações de complicações gestacionais ou de acidentes pessoais ${ }^{9}$, os procedimentos necessários passam a ser eletivos nos termos do contrato do plano de saúde, e não são prontamente cobertos por ele. Situações emergenciais, que foram ampliadas pela lei para abranger casos com risco de lesões irreparáveis, acabam sendo equivocadamente desconsideradas nesses casos, já que os pedidos médicos de internação não costumam qualificar risco do paciente.

Deste modo, autorizações de planos de saúde para a realização de cirurgias urgentes pelos critérios médicos assistenciais, que deveriam ocorrer prontamente, ou no máximo em 24 horas nos termos legais, são negadas ou tratadas como cirurgias eletivas, inclusive com requisição de junta médica para avaliação ${ }^{10}$, imputando mora de meses à resolução do caso. Como nessas situações a espera não é opção, os pacientes recorrem ao judiciário para conseguir a autorização do tratamento, que é concedido em sede de liminar, desde que haja evidência do direito (fumus bonis juris), e da situação de urgência/ emergência, cuja demora pode causar dano irreparável (periculum in mora) $)^{11,12}$.

Em que pese o direito dos planos de saúde aos limites do contrato, esses não podem recusar ou postergar atendimento refugiando-se em interpretações restritivas da lei desconsiderando o real quadro do paciente. A correta identificação e o encaminhamento de pacientes nos serviços de saúde, de acordo com a severidade e complexidade de sua situação clínica, seja ela emergencial ou eletiva, organiza o fluxo de atendimento ${ }^{13}$ e pode aumentar a eficiência do tratamento, diminuindo riscos de danos causados pela espera ${ }^{14}$, inclusive o de óbito $^{15}$. Assim, o objetivo deste trabalho foi discutir a normativa nacional sobre urgência e emergência e avaliar a importância do ato médico na caracterização da gravidade e da extensão do quadro clínico do paciente nos documentos médico-legais para o justo cumprimento dos contratos de saúde.

\section{DESENVOLVIMENTO}

\section{Aspectos Conceituais}

Antes de se avaliar a normativa vigente, é necessário discutir a interpretação conceitual dos termos no contexto brasileiro. Na linguagem do dia a dia, as palavras urgência e emergência são muitas vezes apresentadas como sinônimas. Entretanto, como já foi antecipado na introdução, existem algumas sutilezas que as distinguem.

Por meio de consulta ao Dicionário Aurélio é possível delimitar algumas diferenças entre os termos: urgência pode ser definida como "qualidade do que é urgente, com necessidade imediata", ou seja, denota apenas uma necessidade de ação rápida, enquanto emergência é derivada do verbo emergir, isto é, surgimento ou aparecimento de algo, de forma repentina e inusitada, característica não observável na definição da urgência $^{16}$

Fora do contexto médico, o termo emergência é aplicado para adjetivar situações críticas ou perigosas, como "saída de emergência", que exigem conduta rápida a fim de se evitar circunstâncias perigosas associadas com a terminalidade da vida ${ }^{17}$. Note-se, ainda, que a palavra urgência possui o mesmo radical que "urge", usado em expressões correntes como "urge solucionar" que apresenta a acepção de imediatismo, ou seja, ação que não aceita demora. Desse modo, pode-se concluir que iminência, presteza e celeridade são elementos 
intrínsecos para a definição de "urgência"16.

Grosso modo, mesmo que as distinções observadas a partir de elementos da língua portuguesa permitam elaborar diferenciação razoável entre os termos urgência e emergência, sua aplicação na área médica não se traduz facilmente, principalmente quando se considera a utilização deles ante os riscos, a gravidade ou ao perigo da situação fática.

Em tese, a busca do significado de vocábulos aplicáveis na linguagem médica usualmente encontra amparo em bancos de dados internacionais, como a Biblioteca Virtual em Saúde (BVS) ${ }^{18}$ e o PubMed ${ }^{19}$, que utilizam descritores comuns para a indexação de artigos científicos em saúde, descritores estes com conceito similar em diferentes línguas. Esses termos são organizados em tesauros como o $\mathrm{MeSH}^{20}$, Medical Subject Headings, com curadoria da Biblioteca Nacional de Medicina dos Estados Unidos (US NLM) ${ }^{21}$ ou, na sua contraparte brasileira, DeCS (Descritores em Ciências da Saúde), organizado pelo Centro Latino-Americano e do Caribe de Informação em Ciências da Saúde $(\mathrm{BIREME})^{22}$.

Todavia, tal recurso se mostra deficiente na distinção terminológica, visto que, ao se buscar o descritor para urgência, tanto no MeSH como no DeCS, encontrase como sinônimo emergência. De fato, os descritores encontrados foram emergencies, urgências médicas e emergência, respectivamente em inglês, espanhol e português. A definição em português encontrada no DeCS é a tradução literal do descritor encontrado no MeSH: "Situações ou condições que requerem intervenção imediata para evitar resultados adversos sérios" 23,24 .

Corrobora-se, portanto, o entendimento de que a definição dos termos aqui estudados não configura consenso técnico, muito embora ambos se centrem nos elementos risco à vida ou perigo de morte. $\mathrm{Na}$ esfera normativa, é importante enfatizar que termos polissêmicos devem ser evitados e, neste sentido, a palavra risco é demasiadamente genérica para ser usada, tanto no âmbito clínico como deontológico ou jurídico. Risco é qualidade que pode ser nula ou encontrar-se no infinito de probabilidades até a certeza de sua confirmação. Por exemplo, para existir o risco de morte basta a condição de se estar vivo. Este pode ser baixo, como nos casos de gastroenterites em pessoas sem outras comorbidades, ou alto, em pessoas que enfrentam neoplasias malignas ${ }^{25}$. O correta, portanto, é a utilização do termo perigo, quando o risco de morte for tal que se nenhuma conduta for realizada para impedi-lo, logrará êxito (possibilidade concreta de êxito letal) ${ }^{26}$.

Quando se recorre à literatura em busca da precisão conceitual no contexto da clínica médica, observa-se que há mais de $50 \operatorname{anos}^{27,28}$ a emergência já era tratada com fundamento na necessidade de atenção imediata - casos em que havia perigo à vida do paciente, deixando os casos de urgência àqueles que requeriam atenção imediata, mas sem perigo à vida. Com relação às situações eletivas, elas seriam referentes a agravos menores ou não agudos e sem necessidade de atenção médica imediata. Com efeito, a emergência estaria limitada aos casos em que há perigo de morte, deixando para a urgência condições sérias, mas que não apresentam tal condição ${ }^{29}$.

Martinez-Almoyna, um dos médicos idealizadores do SAMU francês (Service d'Aide Médicale Urgente), e Nitschke apresentaram uma fórmula que resume a qualificação de um evento como urgente, acrescendo o valor social na ponderação multifatorial que também considera fatores técnicos e médicos (gravidade, atenção e tempo) $)^{30}$ :

$$
\begin{aligned}
& {[\mathrm{U}]=\text { urgência }} \\
& {[\mathrm{G}]=\text { gravidade }} \\
& {[\mathrm{U}]=[\mathrm{G}] \times[\mathrm{A}] \times[\mathrm{V}] \times[\mathrm{T}] \quad[\mathrm{A}]=\text { atenção médica }} \\
& {[\mathrm{V}]=\text { valor social }} \\
& {[\mathrm{T}]=\text { tempo }}
\end{aligned}
$$

Sopesa como fator social o contexto da situação, tanto para quem recebe como para quem é responsável pelo atendimento, expondo o "peso" ou a "valência" do caso concreto na sociedade, o que confere certo "status" social das urgências, uma em relação às outras. Um médico, por exemplo, ao longo de sua vida profissional, pode variar seu julgamento sobre a urgência de um caso, de acordo com seus valores e experiência. Em outras situações, a caracterização de urgência acaba sendo dada pela comoção social que traria se assim não fosse tratada.

Os mesmos autores justificam que, ao contrário do que ocorre nas outras línguas latinas e anglosaxônicas, no francês existe apenas a palavra urgences, sendo emergência considerada aquela urgência muito grave $^{30}$. Todavia, independentemente da carência de taxonomia precisa, há consenso quanto à importância da qualificação do evento ante a premência invocada para seu tratamento, e procedimentos eletivos podem ser postergados, enquanto os emergenciais não, ficando as situações urgentes situadas imediatamente após aquelas emergenciais, eventualmente em diversas categorias: urgências graves, urgências vitais, urgências extremas, urgências presumidas, urgências aparentes, urgências subjetivas, entre outras ${ }^{31}$.

E, mesmo na atualidade, embora a ideia persista, os conceitos ainda não se mostram definitivos. Em levantamento extenso sobre o que seriam visitas não urgentes a uma unidade de emergência, não foi encontrada definição universal, apenas constatou-se que essas seriam situações passíveis de serem resolvidas por clínico geral ${ }^{32}$. Em publicação de 2010, do National Center for Health Statistics, visitas não urgentes foram classificadas como aquelas em que os prontuários médicos indicaram que 
o atendimento poderia ter sido proporcionado entre 120 minutos e 24 horas $^{33}$.

Historicamente, observa-se que, na busca pela otimização do atendimento médico, diversas estruturas de triagem foram criadas para classificação do risco de pacientes em hospitais ou em campo, com graduações que separam os casos eletivos daqueles emergenciais e urgentes. São protocolos que utilizam algoritmos para avaliar a gravidade do caso e o tempo máximo de espera por intervenção. A Agência Nacional de Saúde Suplementar (ANS) ${ }^{34}$ reconhece os seguintes sistemas de classificação de pacientes pelo risco: Emergency Severity Index ${ }^{35}$, Modelo Andorrano de Triaje e Sistema Español de Triaje ${ }^{36}$, Australasian Triage Scale ${ }^{37}$, Canadian Triage and Acuity Scale ${ }^{38,39}$ e Protocolo de Manchester ${ }^{40}$. Nesses sistemas, há estratificação dos pacientes em cinco níveis de risco: emergência, muito urgente, urgente, pouco urgente e não urgente, e nos três últimos há definição da terminologia de acordo com a complexidade dos casos e tempo de espera para o atendimento médico: emergência - < 10 minutos; urgência - < 30 minutos; não urgente - < 120 minutos $^{39,40}$.

Há escala simplificada dessa classificação no Brasil, com categorização da emergência apenas para as situações em que a resposta à pergunta "o paciente está morrendo?" seja afirmativa. Ou seja, emergência seria "situação de alto risco, na qual o paciente requer intervenção imediata para que a morte seja evitada"41. E é este o conceito de emergência que predomina quando o assunto é atendimento. Já urgências seriam todas aquelas condições em que a pronta intervenção médica especializada é necessária, sem que haja perigo iminente à vida.

\section{Aspectos Éticos}

Conforme discutido acima, a distinção entre urgência e emergência é extremamente relevante na clínica médica, pois permite: (i) o encaminhamento para serviços especializados; (ii) o estabelecimento de ordem de prioridade no atendimento; (iii) e, em determinadas situações cruciais, a delimitação da cobertura do plano de saúde, assunto que será discutido em momento posterior.

A Resolução do Conselho Federal de Medicina (CFM) $\mathrm{n}^{\circ} 1.451^{1}$ traz a definição de urgência e emergência sob a ótica deontológica, tendo como destinatário o prestador do atendimento em saúde:

Define-se por URGÊNCIA a ocorrência imprevista de agravo à saúde com ou sem risco potencial de vida, cujo portador necessita de assistência médica imediata.

Define-se por EMERGÊNCIA a constatação médica de condições de agravo à saúde que impliquem em risco iminente de vida ou sofrimento intenso, exigindo, portanto, tratamento médico imediato.
A partir da leitura da supracitada resolução, é possível notar que realmente há distinção técnica entre os termos, não sendo plausível o emprego indiscriminado deles. Em Parecer Consulta de 2017, reflete o conselheiro $^{42}$ :

Desse modo, compreende-se a existência de um rol TAXATIVO como arquétipo conceitual e classificador a ser adotado pelas instituições de saúde quando se trata de urgência e emergência. Já a eletividade deve ser compreendida sob o aspecto excludente, ou seja, tudo aquilo que não se encaixa nos critérios de urgência e emergência deve assumir um significado eletivo.

É válido ressaltar que, na definição de urgência trazida pelo CFM, a ação rápida pelo profissional da saúde é o núcleo do conceito, ademais, nota-se que o risco de morte abarcado em tal definição é unicamente potencial, e não precisa estar necessariamente presente para que uma determinada situação seja considerada urgente. Por outro lado, quando se trata de uma emergência, o perigo de morte é evidente. Cabe frisar, no entanto, que é possível que se configure uma emergência médica sem a presença do perigo à vida, nos casos em que há sofrimento intenso pelo paciente. Essas diferenças determinarão, por exemplo, o fluxo de pacientes em unidades de pronto atendimento e nos serviços hospitalares de urgência e emergência ${ }^{43,44}$.

Em resumo, as situações de urgência e de emergência são prioridade absoluta no atendimento de pacientes pelos profissionais de saúde sob o ponto de vista deontológico. Condutas contrárias poderão ser caracterizadas como a omissão de socorro $^{45}$. Resta claro, portanto, que é dever do cirurgião assistente e também sua responsabilidade definir, ante o caso concreto, o imediatismo da necessidade de atendimento, classificando-o como emergencial, urgente ou eletivo ${ }^{46}$.

\section{Aspectos Legais}

A primeira implicação legal de emergência advém do Código Penal Brasileiro, quando trata da omissão de conduta médica nos casos de urgência e emergência:

\section{Omissão de socorro ${ }^{47}$}

Art. 135 - Deixar de prestar assistência, quando possível fazê-lo sem risco pessoal, à criança abandonada ou extraviada, ou à pessoa inválida ou ferida, ao desamparo ou em grave e iminente perigo; ou não pedir, nesses casos, o socorro da autoridade pública:

Pena - detenção, de um a seis meses, ou multa. Parágrafo único - A pena é aumentada de metade, se da omissão resulta lesão corporal de natureza grave, e triplicada, se resulta a morte. (grifa-se) 
No mesmo diapasão, não se tipifica como constrangimento ilegal, a intervenção médica ou cirúrgica, sem o consentimento do paciente ou de seu representante legal quando aquele estiver sob iminente perigo de vida, ou seja, em situações emergenciais é obrigatória a intervenção do médico.

\section{Constrangimento ilegal ${ }^{47}$}

Art. 146 - Constranger alguém, mediante violência ou grave ameaça, ou depois de lhe haver reduzido, por qualquer outro meio, a capacidade de resistência, a não fazer o que a lei permite, ou a fazer o que ela não manda:

Pena - detenção, de três meses a um ano, ou multa. Aumento de pena

$\S 1^{\circ}$ - As penas aplicam-se cumulativamente e em dobro, quando, para a execução do crime, se reúnem mais de três pessoas, ou há emprego de armas.

$\S 2^{\circ}$ - Além das penas cominadas, aplicam-se as correspondentes à violência.

$\S 3^{\circ}$ - Não se compreendem na disposição deste artigo: I - a intervenção médica ou cirúrgica, sem o consentimento do paciente ou de seu representante legal, se justificada por iminente perigo de vida; II - a coação exercida para impedir suicídio. (grifa-se)

Por outro lado, a definição de emergência usada pelos planos de saúde é aquela dada no art. 35-C da Lei $\mathrm{n}^{\circ} 9.656^{9}$, estabelecendo como obrigatória a cobertura do atendimento em casos:

I - de emergência, como tal definidos os que implicarem risco imediato de vida ou de lesões irreparáveis para o paciente, caracterizado em declaração do médico assistente;

II - de urgência, assim entendidos os resultantes de acidentes pessoais ou de complicações no processo gestacional;

III - de planejamento familiar.

Assim, percebe-se a distinção entre os conceitos trabalhados pelos planos de saúde e aqueles adotados pelo $\mathrm{CFM}^{1}$, principalmente em relação ao conceito de urgência. Diga-se, inicialmente, que a definição trazida pela referida lei restringe o termo urgência, abarcando apenas duas hipóteses: acidentes pessoais e complicações da gestação, afastada a caracterização atestada pelo médico.

Em contraste, na definição empregada pelo CFM, não há qualquer delimitação de circunstância, sendo necessário apenas que haja um agravo imprevisto no estado de saúde do paciente. Caberá ao médico avaliar o caso e enquadrá-lo como urgente. Desse modo, é possível interpretar que a Lei $\mathrm{n}^{\circ} 9.656^{9}$ tenha restringido o significado de "imprevisto" trabalhado pelo CFM, indicando que o evento inesperado somente possa ser decorrente de acidentes pessoais ou complicações da gestação.

No tocante ao termo emergência, comparando-se as definições dadas pela Lei $\mathrm{n}^{\circ} 9.656^{9}$ e pelo $\mathrm{CFM}^{1}$, notase que ambas se valem do elemento "risco iminente de vida", na verdade, à vida. Contudo, abarcam elementos com tangibilidade distintas. Enquanto a lei dos planos de saúde ${ }^{9}$ também considera como emergenciais os casos de "lesões irreparáveis", o CFM ${ }^{1}$ estende o conceito àquelas situações de sofrimento intenso.

Como consequência, tem-se que os pedidos de procedimentos médicos para os planos de saúde descrevem a situação clínica do paciente conforme os ditames médico-legais, por exemplo, urgência na realização de uma biópsia excisional, e a autorização para cobertura os interpreta ante a legislação pertinente ${ }^{9}$, negando-os por não se tratarem de casos gestacionais ou de acidentes pessoais, ignorando o risco de causarem lesões irreparáveis. O próprio sistema da operadora, ao receber os dados do pedido, qualifica o procedimento como eletivo pelo código TUSS ${ }^{48}$ (Terminologia Unificada da Saúde Suplementar) da conduta requisitada. Senão, vejamos:

Impende salientar que o médico que acompanha a Requerente informou, no relatório de fls. 87, que há risco de alta progressão da doença, o que não se equipara a lesão irreparável. Ora, Excelência! A possibilidade de progressão da doença não significa que a mesma não mais poderá ser curada, razão pela qual, ainda assim, não resta caracterizada a situação de emergência da cirurgia prescrita à Requerente. Ademais, consideram-se como procedimento de urgência aqueles resultantes de acidentes pessoais, entendidos como aqueles prestados imediatamente após o evento, o que, definitivamente, não é o caso dos autos. ${ }^{49}$

Esse excerto de contestação refere-se a ação em que houve negativa ao pedido médico para a pronta realização de mastectomia de paciente diagnosticada com carcinoma de mama, cujo relatório prescrevia ser "necessário tratamento urgente" "devido a risco de progressão da doença". Ainda, em todas as guias de solicitação de internação houve destaque para a palavra "urgente" no topo do documento. Mesmo assim, o plano de saúde refutou o pedido médico por considerá-lo eletivo:

OS PROCEDIMENTOS DE CARÁTER ELETIVO SÃO AQUELES EM QUE SE CONSEGUE ESCOLHER A MELHOR DATAPARA SE REALIZAR O PROCEDIMENTO CIRÚRGICO. GERALMENTE ELA É REALIZADA APÓS DIVERSOS EXAMES, QUE SÃO FEITOS PARA OBTER AS MELHORES CONDIÇÕES DE SAÚDE DO PACIENTE, E 


\section{DEPENDEM DA AGENDA DO MÉDICO E DO HOSPITAL, O QUE DE FATO OCORREU NO CASO PRESENTE ${ }^{49}$.}

Assim, casos como esse acabam por ter sua cobertura nos prazos legais negada, apenas por não serem decorrentes de acidentes pessoais ou de gestação - passam a ser eletivos ante os planos de saúde. Na referida ação, a sentença garantiu a tutela à paciente com convencimento do magistrado de que a real situação clínica seria a de emergência:

Conforme a própria contestação alega "CONSIDERAMSE ATENDIMENTOSDE EMERGÊNCIA AQUELES QUE IMPLICAREM RISCO IMEDIATO DE VIDA OU DE LESÕES IRREPARÁVEIS" (fls. 109). Não é preciso ser especialista da área da saúde para saber que a patologia que acomete a autora, câncer, se não tratado com a máxima brevidade, causa ao paciente grandes danos à sua saúde, chegando, em muitos casos, à morte ${ }^{49}$.

Deve-se salientar que o projeto de lei (PL) que originou a Lei $\mathrm{n}^{\circ} 9.565^{9}$, o PL 4.425 de $1994^{50}$, não trazia em seu bojo uma nova interpretação conceitual sobre o diagnóstico da gravidade e complexidade dos casos clínicos. Ocorre que diversos outros projetos versando sobre a mesma matéria foram apensados a este $\left(\mathrm{n}^{\text {os }}\right.$ 929/91, 4.214/93, 4.417/94, 4.572194, 237/95, 852/95, 944/95, 1.289/95, 1.390/95, 1.405/96, 1.930/96, 1.975/96, $2.104 / 96, \quad 2.419 / 96,2.420 / 96, \quad 2.870 / 97, \quad 3.079 / 97$, 3.160/97, 3.581/97, 3.586/97, 3.607/97 e 3.617/97), bem como Emendas de Plenário e, ao final, isso resultou em inovação terminológica ao texto da lei ${ }^{51}$.

\section{Jurisprudência - Implicações práticas da definição}

A distinção entre urgência e emergência não permeia apenas a seara conceitual, pois, na prática, possui consequências reais aos consumidores de planos de saúde, que serão apresentadas a partir da jurisprudência do Tribunal de Justiça de São Paulo (TJSP) ${ }^{52}$. Cabe ressaltar que os julgados selecionados servem apenas a título de exemplo e não pretendem esgotar o rol de casos no Estado de São Paulo, apenas pincelam os conceitos trabalhados em questões litigiosas mais recorrentes.

Um dos exemplos a demonstrar a importância prática da distinção de conceitos apresentada neste trabalho é a negativa de cobertura de despesas médicas de profissionais não conveniados ou de despesas hospitalares fora da rede conveniada em situações de urgência, com base no argumento de que os procedimentos realizados não se encaixam nas definições dadas pela Lei n ${ }^{\circ} 9.656^{9}$, em tentativa de se esquivar da legislação protetiva ao consumidor, que prevê esse tipo de cobertura:
Art. 12. São facultadas a oferta, a contratação e a vigência dos produtos de que tratam o inciso I e o § $1^{\circ}$ do art. $1^{\circ}$ desta Lei, nas segmentações previstas nos incisos I a IV deste artigo, respeitadas as respectivas amplitudes de cobertura definidas no plano-referência de que trata o art. 10, segundo as seguintes exigências mínimas:

[...] VI - reembolso, em todos os tipos de produtos de que tratam o inciso I e o $\S 1^{\circ}$ do art. $1^{\circ}$ desta Lei, nos limites das obrigações contratuais, das despesas efetuadas pelo beneficiário com assistência à saúde, em casos de urgência ou emergência, quando não for possível a utilização dos serviços próprios, contratados, credenciados ou referenciados pelas operadoras, de acordo com a relação de preços de serviços médicos e hospitalares praticados pelo respectivo produto, pagáveis no prazo máximo de trinta dias após a entrega da documentação adequada;

$\mathrm{Na}$ decisão abaixo relacionada, o autor foi obrigado a buscar atendimento urgente de forma particular, já que o procedimento foi negado pelo plano e não havia, na rede, profissionais capacitados para realizar a delicada cirurgia. Como usuário, buscou, no judiciário, o ressarcimento pelos valores desembolsados ${ }^{53}$ :

APELAÇÃO - PLANO DE SAÚDE - Ação de ressarcimento dos valores desembolsados para pagamento de procedimento cirúrgico de emergência - Sentença que julgou procedente o pedido do autor Recurso de apelação da ré - Demora para autorização de procedimento cirúrgico emergencial, nos termos de decisão judicial - Abusividade que afronta ao Código de Defesa do Consumidor - Cobertura devida - Ressarcimento integral das despesas médicas, independentemente dos limites estabelecidos no contrato - Vedação à fixação de cláusulas que prevejam reembolso dos honorários médicos sem conter parâmetros objetivos e claros para o cálculo dos valores a restituir - Afronta ao Código de Defesa do Consumidor (arts. $6^{\circ}, \mathrm{IV}, 14,46$ e $54, \S 4^{\circ}$ ) - Dano moral configurado - Precedente do STJ - Valor proporcional e razoável Decisão mantida - Recurso desprovido.

(TJSP. Apelação $\mathrm{n}^{\circ}$ 1001481-32.2016.8.26.0127. Relator: Des. Costa Netto; $9^{\mathrm{a}}$ Câmara de Direito Privado. Julgado em: 27/06/2017).

Trata-se de caso em que, adimplente de suas obrigações contratuais, o autor, que era conveniado do plano por anos, portanto inequivocamente fora do prazo de carência, buscou atendimento na sua rede credenciada para resolução de quadro agudo em seu olho esquerdo. Em certo momento, foi diagnosticado com trauma ocular contuso, sendo recomendada "cirurgia de catarata no olho esquerdo com deslocamento de retina, associado com buraco muscular". Foi encaminhado por médico conveniado para cirurgia com urgência (vitrectomia e retinopexia), em função do risco de perder a visão do 
olho esquerdo de forma irreversível e irreparável.

Perante a negativa e a ausência de médicos credenciados capacitados para executar os procedimentos, o autor da ação foi obrigado a custeá-los de forma particular. A decisão que concedeu a tutela sustentou:

Ressalte-se que, ainda que procedimento emergencial tenha sido realizado com profissional não credenciado ao plano de saúde, admite-se o reembolso integral haja vista que o contrato entabulado entre as partes, às fls. 78/79, prevê metodologia extremamente dificultosa e trabalhosa para o consumidor ter ciência do valor que será reembolsado a título de honorários médicos ${ }^{53}$.

Também são comuns no judiciário casos em que se desconsidera a condição de emergência/urgência durante o período de carência do plano, buscando afastar a responsabilidade do custeio dos procedimentos ${ }^{9}$ :

Art. 12. São facultadas a oferta, a contratação e a vigência dos produtos de que tratam o inciso I e o $\S$ $1^{\circ}$ do art. $1^{\circ}$ desta Lei, nas segmentações previstas nos incisos I a IV deste artigo, respeitadas as respectivas amplitudes de cobertura definidas no plano-referência de que trata o art. 10, segundo as seguintes exigências mínimas: [...] V - quando fixar períodos de carência: [...] c) prazo máximo de vinte e quatro horas para a cobertura dos casos de urgência e emergência;

Neste sentido ${ }^{54}$ :

Apelação - Plano de saúde - Negativa de cobertura para internação da autora, diagnosticada com enterorragia de grande volume - Situação de urgência e emergência que afasta a carência - Aplicação dos artigos 12, inciso $\mathrm{V}$, letra "c" e 35-C da Lei no 9.656/98 - Recusa abusiva Danos morais configurados - Negativa que ocorreu sem qualquer consideração ao quadro clínico da paciente menor - Os juros de mora sobre o valor da condenação por dano moral deverão incidir do arbitramento Indenização por dano moral que comporta majoração para R\$20.000,00 - Sentença parcialmente modificada - Recursos parcialmente providos.

(TJSP. Apelação $\mathrm{n}^{\mathrm{o}}$ 1001218-42.2016.8.26.0404. Relator: Des. Luis Mario Galbetti. $7^{\text {a }}$ Câmara de Direito Privado. Julgado em: 23/01/2018).

No caso acima, a criança teve negado seu pedido de internação (a) que era urgente, (b) com origem em hemorragia intestinal e (c) tendo o contrato mais de 30 dias. Alegou-se que o contrato expressamente identificava período de carência de 180 dias para internação, ignorando completamente a situação de urgência prescrita pela médica pediatra e a carência legal de 24 horas. Refere o plano, em contestação ${ }^{55}$, que a cláusula contratual que estipula prazo de 24 horas prescrito na alínea "c", do inciso 5 do art. 12 da Lei $\mathrm{n}^{\circ} 9.565^{9}$ seria limitado a 12 horas de atendimento ambulatorial, mesmo em casos de emergência, dando interpretação restritiva e equivocada ao art. $2^{\circ}$ da Resolução do Conselho de Saúde Suplementar (CONSU) n ${ }^{0} 13^{56}$, que não refere o período de carência:

Art. $2^{\circ} \mathrm{O}$ plano ambulatorial deverá garantir cobertura de urgência e emergência, limitada até as primeiras 12 (doze) horas do atendimento.

Parágrafo único. Quando necessária, para a continuidade do atendimento de urgência e emergência, a realização de procedimentos exclusivos da cobertura hospitalar, ainda que na mesma unidade prestadora de serviços e em tempo menor que 12 (doze) horas, a cobertura cessará, sendo que a responsabilidade financeira, a partir da necessidade de internação, passará a ser do contratante, não cabendo ônus à operadora.

O mesmo texto, no $\S 1^{\circ}$ do art. $3^{\circ}$, impõe que no período de carência de internação dos planos hospitalares, ou seja, nas primeiras 24 horas nos casos de urgência e de emergência, e em até 180 dias para os demais casos, é obrigatória a mesma cobertura dada aos planos ambulatoriais, aquela descrita acima, que garante atenção que não requeira internação nas primeiras 12 horas do atendimento. Observa-se que esse parágrafo restringe a garantia apenas aos casos de emergência. No parágrafo e artigo seguintes, mantém-se a carência de 24 horas para os casos de urgência decorrente de acidentes pessoais e ocorrências gestacionais, respectivamente ${ }^{56}$.

Art. $3^{\circ}$ Os contratos de plano hospitalar devem oferecer cobertura aos atendimentos de urgência e emergência que evoluírem para internação, desde a admissão do paciente até a sua alta ou que sejam necessários à preservação da vida, órgãos e funções.

$\$ 1^{\circ}$. No plano ou seguro do segmento hospitalar, quando o atendimento de emergência for efetuado no decorrer dos períodos de carência, este deverá abranger cobertura igualmente àquela fixada para o plano ou seguro do segmento ambulatorial, não garantindo, portanto, cobertura para internação.

$\S 2^{\circ}$. No plano ou seguro do segmento hospitalar, o atendimento de urgência decorrente de acidente pessoal, será garantido, sem restrições, após decorridas 24 (vinte e quatro) horas da vigência do contrato.

Art. $4^{\circ}$ Os contratos de plano hospitalar, com ou sem cobertura obstétrica, deverão garantir os atendimentos de urgência e emergência quando se referirem ao processo gestacional.

Parágrafo único. Em caso de necessidade de assistência médica hospitalar decorrente da condição gestacional de pacientes com plano hospitalar sem cobertura obstétrica ou com cobertura obstétrica - porém ainda cumprindo período de carência - a operadora estará obrigada a cobrir o atendimento prestado nas mesmas condições 
previstas no art. $2^{\circ}$ para o plano ambulatorial.

No caso da criança cuja internação foi negada, seu plano era hospitalar, havia indicação médica de urgência, e o período de carência para internação havia sido completamente adimplido. Em sentença, o juiz considerou abusiva a cláusula que restringiu a internação em caso de urgência e emergência ${ }^{55}$, fundamentam-se, além do art. 12, V, "c" ", na Súmula $n^{\circ} 103^{57}$ do TJSP e no princípio da boa-fé:

É abusiva a negativa de cobertura em atendimento de urgência e/ou emergência a pretexto de que está em curso período de carência que não seja o prazo de 24 horas estabelecido na Lei n. 9.656/98.

Assim, a sentença que determinou a cobertura, foi mantida em segundo grau com o argumento que se segue 54.

Uma vez atestada a urgência médica, é abusiva a restrição imposta, pois de acordo com o art. 12, inciso $\mathrm{V}$, letra c da Lei 9.656/98, o plano de saúde não pode negar cobertura para casos de urgência médica. Também o art. 35-C da mesma Lei determina que é obrigatória a cobertura de atendimento nos casos de urgência e emergência. [...]

A recusa da ré colocou em risco a saúde e a qualidade de vida da autora no momento da vida em que ele mais precisava de assistência à saúde. A negativa ocorreu sem qualquer consideração ao quadro clínico da paciente.

No caso abaixo relacionado, em outra situação de urgência médica ignorada pelo plano por não se tratar de urgência ou emergência conforme prescrito na Lei $\mathrm{n}^{\circ}$ $9.656^{9}$ (tratava-se de paciente com câncer de cólon com prescrição de cirurgia urgente), a intervenção foi negada por estar o usuário ainda no prazo de carência de 180 dias. Sustentou, a ré, que ${ }^{58}$ :

[...] a moderna jurisprudência não dá suporte ao pleito da autora e, ainda, suscitou-se a relevância da distinção entre "urgência" e "emergência" dada pela lei 9.656/98, sendo que apenas a primeira teria cobertura irrestrita.

Em sua decisão, o magistrado destacou a irrelevância semântica dos termos urgência e emergência ante os efeitos jurídicos da conduta pleiteada, fundamentando-se nos arts. 12 e 35-C da Lei n ${ }^{\circ} 9.656^{9}$, e na seguinte jurisprudência ${ }^{58}$ :

"DIREITO DO CONSUMIDOR. PLANO DE SAÚDE. PERÍODO DE CARÊNCIA. SITUAÇÕES EMERGENCIAIS GRAVES. NEGATIVA DE COBERTURA INDEVIDA. I - Na linha dos precedentes desta Corte, o período de carência contratualmente estipulado pelos planos de saúde, não prevalece, excepcionalmente, diante de situações emergenciais graves nas quais a recusa de cobertura possa frustrar o próprio sentido e razão de ser do negócio jurídico firmado. II - No caso dos autos o seguro de saúde foi contratado em 27/10/03 para começar a viger em $1 \% / 12 / 03$, sendo que, no dia 28/01/04, menos de dois meses depois do início da sua vigência e antes do decurso do prazo de 120 dias contratualmente fixado para internações, o segurado veio a necessitar de atendimento hospitalar emergencial, porquanto, com histórico de infarto, devidamente informado à seguradora por ocasião da assinatura do contrato de adesão, experimentou mal súbito que culminou na sua internação na UTI. III - Diante desse quadro não poderia a seguradora ter recusado cobertura, mesmo no período de carência”. (Resp. n 1.055.199 SP, Min Rel. Sidney Beneti julgado em 03/05/2011).

[...] “CIVIL E PROCESSUAL. ACÓRDÃO ESTADUAL. NULIDADE NÃO CONFIGURADA. PLANO DE SAÚDE. CARÊNCIA. TRATAMENTO DE URGÊNCIA. RECUSA. ABUSIVIDADE. CDC, ART. 51, I. (...) III. Lídima a cláusula de carência estabelecida em contrato voluntariamente aceito por aquele que ingressa em plano de saúde, merecendo temperamento, todavia, a sua aplicação quando se revela circunstância excepcional, constituída por necessidade de tratamento de urgência decorrente de doença grave que, se não combatida a tempo, tornará inócuo o fim maior do pacto celebrado, qual seja, o de assegurar eficiente amparo à saúde e à vida. IV. Recurso especial conhecido em parte e provido." (REsp 466.667/SP, Rel. Min. ALDIR PASSARINHO JUNIOR, QUARTA TURMA, DJ de 17/12/2007);

"PLANO DE SAÚDE. Prazo de carência. Internação de urgência. O prazo de carência não prevalece quando se trata de internação de urgência, provocada por fato imprevisível causado por acidente de trânsito. Recurso conhecido e provido". (REsp 222.339/PB, Rel. Min. RUY ROSADO DE AGUIAR, QUARTA TURMA, DJ $12 / 11 / 2001)$

Cita, ainda, o pronunciamento do Ministro Antônio Cezar Peluzo, quando desembargador do TJSP, sobre a interpretação de contratos como o da espécie ${ }^{58}$ :

“(...) não se pode reduzir tais contratos aos padrões dos negócios governados apenas pela lógica dos lucros. É preciso ir além, enxergar um pouco mais alto, no sistema jurídico-normativo, e deixar-se iluminar pelos princípios que se radicam na dignidade da pessoa humana, hoje sublimada à condição constitucional de fundamento da República (artigo $1^{\circ}$, caput, III, da Constituição), e perante a qual devem justificar-se as normas jurídicas e toda a juridicidade" ( $\mathrm{AC} \mathrm{n}^{\circ} 52.273$ 4/5. Julgado em: 09/02/1999)".

A decisão foi confirmada em $2^{\text {a }}$ instância ${ }^{59}$ : 
Apelação - Ação de obrigação de fazer - Plano de saúde - Necessidade de realização de cirurgia urgente para tratamento de câncer - Recusa da operadora - Mesmo vigente a carência, não se pode limitar a realização do exame para os casos de urgência ou emergência Aplicação do artigo 12, V, 'c', da Lei no 9.656/1998, o qual estabelece que, em casos de urgência ou emergência, o prazo de carência é de, no máximo, 24 (vinte e quatro) horas - Impossibilidade de as cláusulas restritivas de direito representarem ônus excessivo para o consumidor - Contrato de adesão submetido aos ditames do Código de Defesa do Consumidor Doutrina e Jurisprudência - Verba honorária - Fixação que honra as disposições do art. 20 ritual - Recurso Improvido.

(TJSP. Apelação $\mathrm{n}^{\circ} \quad$ 0022453-97.2011.8.26.0003; Relator: Des. Beretta da Silveira; Órgão Julgador: $3^{\mathrm{a}}$ Câmara de Direito Privado; Julgado em: 29/01/2013)

A jurisprudência citada enfatiza a importância da caracterização do quadro clínico pelo profissional da área da saúde de forma extensiva, respeitando-se tanto a normativa administrativa como legal (Quadros 1 e 2), afastando o ônus do paciente em comprovar que não se trata de procedimento eletivo. Mesmo os quadros de urgência médica, perante a Lei $\mathrm{n}^{\circ} 9.656^{9}$, podem ser caracterizados como emergência, já que requerem pronta conduta para evitar dano ou limitá-lo, nos termos legais - "risco de danos irreparáveis". A incompleta caracterização do caso clínico pelo médico pode gerar negativa ou demora na autorização dos procedimentos, sustentadas no próprio documento médico-legal ${ }^{60}$ :

\section{PLANO DE SAÚDE - PROCEDIMENTO CIRÚRGICO - PRESCRIÇÃO QUE NÃO FOI DADA EM REGIME DE URGÊNCIA OU EMERGÊNCIA Autorização antes mesmo do deferimento da tutela provisória e dentro do prazo regulamentar de 21 dias úteis, a contar da solicitação Inexistência de ato ilícito Decisão mantida Recurso improvido." (TJSP. Apelação n ${ }^{\circ}$ 1017992-83.2016.8.26.0005. 5 ${ }^{\text {a }}$ Câmara de Direito Privado. Relator: Des. Fábio Podestá. Julgado em: 11/10/17).}

Ao serem considerados eletivos, os casos passam a sofrer a aplicação dos prazos carenciais legais e submetem-se aos prazos do art. $3^{\circ}$, XIII, da Resolução Normativa $\mathrm{n}^{\circ} 259$, da $\mathrm{ANS}^{61}$ :

Art. $3^{\circ} \mathrm{A}$ operadora deverá garantir o atendimento integral das coberturas referidas no art. $2^{\circ}$ nos seguintes prazos:

I - consulta básica - pediatria, clínica médica, cirurgia geral, ginecologia e obstetrícia: em até 7 (sete) dias úteis;

II - consulta nas demais especialidades médicas: em até 14 (quatorze) dias úteis,

III - consulta/sessão com fonoaudiólogo: em até
10 (dez) dias úteis;

IV - consulta/sessão com nutricionista: em até 10 (dez) dias úteis;

V - consulta/sessão com psicólogo: em até 10 (dez) dias úteis;

VI - consulta/sessão com terapeuta ocupacional: em até 10 (dez) dias úteis;

VII - consulta/sessão com fisioterapeuta: em até 10 (dez) dias úteis;

VIII - consulta e procedimentos realizados em consultório/clínica com cirurgião-dentista: em até 7 (sete) dias úteis;

IX - serviços de diagnóstico por laboratório de análises clínicas em regime ambulatorial: em até 3 (três) dias úteis;

$\mathrm{X} \quad$ - demais serviços de diagnóstico e terapia em regime ambulatorial: em até 10 (dez) dias úteis;

XI - procedimentos de alta complexidade - PAC: em até 21 (vinte e um) dias úteis;

XII - atendimento em regime de hospital-dia: em até 10 (dez) dias úteis;

XIII - atendimento em regime de internação eletiva: em até 21 (vinte e um) dias úteis; e

XIV - urgência e emergência: imediato.

$\S 1^{\circ}$ Os prazos estabelecidos neste artigo são contados a partir da data da demanda pelo serviço ou procedimento até a sua efetiva realização.

No último caso a ser apresentado, uma ação de ressarcimento de valores, o paciente arcou com os gastos de cirurgia urgente (exérese do tumor de pavilhão auricular de crescimento agressivo) pelo fato de o plano de saúde ter proposto agendamento fora dos prazos legais ${ }^{62}$ :

Apelação Plano de Saúde - Ação de ressarcimento dos valores desembolsados para pagamento de procedimento cirúrgico de emergência - Sentença que julgou parcialmente procedente o pedido do autor - Recursos de apelação do autor e do réu. Demora para a realização de procedimento cirúrgico emergencial, colocando em risco a vida do paciente - Abusividade que afronta ao Código de Defesa do Consumidor - Cobertura devida - Sentença mantida; Ressarcimento dos honorários médicos limitados aos critérios estabelecidos em contrato - Vedação a fixação de clausulas que preveem reembolso dos honorários médicos sem conter parâmetros objetivos claros para o cálculo dos valores a restituir - Afronta ao Código de Defesa do Consumidor (art. $6^{\circ}, \mathrm{IV}, 14,46$ e $54 \S 4^{\circ}$ ) - Sentença reformada para determinar o ressarcimento integral dos valores pleiteados na inicial [...] (TJSP. Processo $\mathrm{n}^{\circ}$ 10126108620148260100. Relator: Costa Netto. Julgado em: 30/08/2016).

Muito embora não tenha havido negativa de autorização, e sim sua consideração como procedimento eletivo ou de alta complexidade (atendimento em até 21 dias úteis), diante da agressividade documentada 
Mena H et al. Urgência e Emergência: os conceitos frente às normas administrativas e legais e suas implicações.

do caso, realizou-se o procedimento prontamente, com custo honrado pelo paciente, na própria rede credenciada do plano e com execução pelo médico do serviço. Nesse caso, entendeu o tribunal que os custos havidos deveriam ser plenamente arcados pelo plano, visto que se tratava claramente de caso emergencial:
[...] patente o caráter emergencial no atendimento ao beneficiário, por óbvio, não se pode privilegiar o respeito à cláusula contratual, unilateralmente elaborada pela operadora de plano de saúde, em detrimento do direito do consumidor de buscar preservação da própria vida, quando da ocorrência de emergência médica [...].

Quadro 1. Distinção conceitual de urgência de acordo com a Lei dos Planos de Saúde e o Conselho Federal de Medicina ${ }^{1,9}$

\begin{tabular}{|c|c|c|}
\hline & \multicolumn{2}{|r|}{ URGÊNCIA } \\
\hline & Lei $n^{0}$ 9.656/98 & Resolução CFM no 1.451/95 \\
\hline Perigo de MORTE & INDEPENDE & Pode estar presente, mas não é determinante \\
\hline Atendimento imediato & Até 24 horas & SIM \\
\hline Ocorrência imprevista & INDEPENDE & SIM \\
\hline Acidentes pessoais & SIM & INDEPENDE \\
\hline Processo gestacional & SIM & INDEPENDE \\
\hline
\end{tabular}

Quadro 2. Distinção conceitual de emergência de acordo com Lei dos Planos de Saúde e o Conselho Federal de Medicina ${ }^{1,9}$

\begin{tabular}{|l|l|l|}
\hline \multirow{2}{*}{} & \multicolumn{2}{|c|}{ EMERGÊNCIA } \\
\cline { 2 - 3 } & Lei $\mathbf{n}^{\mathbf{0}} \mathbf{9 . 6 5 6 / 9 8}$ & Resolução CFM $\mathbf{n}^{\mathbf{0}} \mathbf{1 . 4 5 1 / 9 5}$ \\
\hline Perigo de MORTE & Presente & Presente \\
\hline Atendimento imediato & Até 24 horas & SIM \\
\hline Sofrimento intenso & NÃO AVALIA & Presente \\
\hline Risco de lesões irreparáveis para o paciente & Presente & NÃO AVALIA \\
\hline
\end{tabular}

Por fim, ressalta-se que, diante do grande número de processos envolvendo planos de saúde nos tribunais brasileiros, iniciou-se processo de aprovação de súmulas referentes a contratos de planos e seguros de saúde com o intuito de combater a abusividade de operadoras e buscar estabelecer uma jurisprudência protetiva aos assegurados em situação de urgência e emergência. Nesse sentido, destacam-se as Súmulas dos Tribunais do Ceará ${ }^{63}$ (TJCE), São Paulo, Rio de Janeiro ${ }^{64}$ (TJERJ) e Pernambuco ${ }^{65}$ (TJPE) (Quadro 3):

Quadro 3. Enunciados dos Tribunais brasileiros referentes a obrigatoriedade de cobertura de tratamento em casos de urgência, emergência e em período de carência ${ }^{52,63-65}$

\begin{tabular}{|c|l|}
\hline \multicolumn{1}{|c|}{ TJERJ } & \multicolumn{1}{c|}{ TJCE } \\
\hline $\begin{array}{l}\text { 337. A recusa indevida, pela operadora de planos de saúde, } \\
\text { de internação em estado de emergência/urgência gera dano } \\
\text { moral in re ipsa. }\end{array}$ & $\begin{array}{l}\text { 40. É abusiva a negativa de cobertura por plano de saúde } \\
\text { em atendimento de urgência ou emergência a pretexto de } \\
\text { estar em curso período de carência que não seja o prazo de } \\
24 \text { horas estabelecido na Lei no 9.656/98. }\end{array}$ \\
\hline \multicolumn{1}{|c|}{ TJPE } & \multicolumn{1}{c|}{ TJSP } \\
\hline $\begin{array}{l}\text { 136. É abusiva a negativa de internamento para cirurgia de } \\
\text { urgência e emergência, ainda que o contrato de assistência à à } \\
\text { saúde esteja em período de carência. }\end{array}$ & $\begin{array}{l}\text { 103. É abusiva a negativa de cobertura em atendimento } \\
\text { de urgência e/ou emergência a pretexto de que está em } \\
\text { curso período de carência que não seja o prazo de 24 horas } \\
\text { estabelecido na Lei n. 9.656/98. }\end{array}$ \\
\hline
\end{tabular}




\section{CONSIDERAÇÕES FINAIS}

O presente trabalho mostrou que as diferenças conceituais entre os termos urgência e emergência refletem as diferenças da normativa do CFM e do Ministério da Saúde, emergência sendo característica de situação crítica e perigosa, que deve receber atenção imediata por envolver perigo de morte. Já urgência, embora exija atenção rápida, traz intrinsecamente a ideia de risco e, não, certeza de perigo à integridade do indivíduo.

Com a regulamentação dos planos de saúde pela Lei $n^{\circ} 9.656^{9}$, restringiu-se a ocorrência de urgência, para fins de cobertura de atendimento, àqueles casos oriundos de acidentes pessoais e processos gestacionais. Emergências, por outro lado, passaram a ser caracterizadas não só pelo inerente perigo de morte, mas pelo risco de o paciente sofrer lesões irreparáveis. O sofrimento intenso, considerado emergencial pela normativa administrativa, não foi contemplado na legislação da saúde suplementar, e alterou-se o prazo de atendimento, que passou de imediato para até 24 horas, tanto nos casos emergenciais quanto nos urgentes.

A jurisprudência selecionada demonstrou a importância de o médico caracterizar a situação clínica extensamente, incluindo o risco da ocorrência de lesões irreparáveis de forma concreta já que, se assim não o fizer, exporá o paciente a não ter sua situação clínica reconhecida, perdendo direito à cobertura de procedimentos uma vez que não se comprove situação de emergência ou urgência, pois:

a) o prazo de carência para internações passa a ser de 180 dias e não de 24 horas;

b) não há cobertura de procedimentos, recursos humanos e materiais de condutas realizadas fora da rede credenciada;

c) os prazos de garantia de atendimento passam a ser os da Resolução Normativa 259, da ANS (e não 24 horas);

Em que pese a alteração conceitual terminológica trazida pela legislação da saúde suplementar, se os documentos médico-legais forem preenchidos de maneira extensiva, com fundamentação hígida sobre os riscos de que a omissão de atendimento venha a causar danos irreparáveis, os casos urgentes que não se enquadram na legislação da saúde suplementar passarão a ter cobertura emergencial por ela, reforçando a importância da correta redação de relatórios e pedidos médicos para internação, realização de exames, procedimentos ou aquisição de medicamentos, com destaque para os quimioterápicos. Esses documentos evitam negativas equivocadas por falta de informação e, ainda, constituem-se em prova, perante a Justiça, da caracterização do perigo da demora em se honrar o direito à saúde e, por vezes, à vida, nos termos do contrato celebrado, da legislação vigente e da Constituição.

Mena H, Piacsek GVM, Motta MV. Urgency and Emergency. The concepts in the administrative and legal regulations and their impact on the clinical medicine. Saúde, Ética \& Justiça. 2017;22(2):81-94.

\begin{abstract}
The emergency and the urgent situation present distinct concepts for those who provide medical service, for those who receive it, for those who pay for it and for those who legislate on the matter. Conceptual distinctions found in prepaid health plan legislation and in administrative regulations require that the health professional, in his requests for exams, procedures, and hospitalizations, extensively describe the clinical situation, to prevent the situation where the patient is left with the burden of proving his need for prompt healthcare to the health care provider or in court. This is because Federal Law 9.656 restricted the concept of urgency to situations of personal accidents and gestational complications and excluded situations of intense suffering from emergencies. It expanded, however, the concept of emergencies so that the health plan has to cover cases where there is a risk of irreparable damage to the patient. It provided an extended definition for immediate treatment, which could be offered within 24 hours. The studied jurisprudence indicated the importance of medico-legal documents for characterizing the clinical condition of the patient and guaranteeing his rights with respect to his health plan contract.
\end{abstract}

KEY WORDS: Prepaid Health Plans; Emergencies; Acts of Administration; Health legislation; Delivery of Health Care; Health Law.

\title{
REFERÊNCIAS
}

1. Conselho Federal de Medicina (CFM). Resolução CFM n 1.451, de 10 de março de 1995 [Internet]. Brasília; 1995 [acesso em 2018 jan. 8]. Disponível em: http://www. portalmedico.org.br/resolucoes/cfm/1995/1451 1995.htm

2. Brasil. Ministério da Saúde. Gabinete do Ministro. Portaria $\mathrm{n}^{\circ}$ 354, de 10 de março de 2014. Publica a proposta de Projeto de Resolução "Boas Práticas para Organização e Funcionamento de Serviços de Urgência e Emergência [Internet]. Brasília; 2014 [acesso em 2018 jan. 8]. Disponível em: http://bvsms.saude.gov.br/bvs/saudelegis/ gm/2014/prt0354_10_03_2014.html

3. Brasil. Ministério da Saúde. As Redes de Atenção à Saúde [Internet]. Brasília; 2018. [acesso em 2018 jan. 8]. Disponível em: http://dab.saude.gov.br/portaldab/smp_ras. 
php

4. Brasil. Ministério da Saúde. Portaria $\mathrm{n}^{\circ} 4.279$, de 30 de dezembro de 2010. Estabelece diretrizes para a organização da Rede de Atenção à Saúde no âmbito do Sistema Único de Saúde (SUS) [Internet]. Brasília; 2010 [acesso em 2018 jan. 8]. Disponível em: http://conselho.saude.gov.br/ultimas noticias/2011/img/07_jan_portaria4279_301210.pdf

5. Brasil. Ministério da Saúde. Portaria $n^{0} 1.600$, de 7 de julho de 2011. Reformula a Política Nacional de Atenção às Urgências e institui a Rede de Atenção às Urgências no Sistema Único de Saúde (SUS) [Internet]. Brasília; 2011 [acesso em 2018 jan. 8]. Disponível em: http://bvsms.saude. gov.br/bvs/saudelegis/gm/2011/prt1600_07_07_2011.html

6. Brasil. Ministério da Saúde. Política Nacional de Atenção às Urgências [Internet]. Brasília: Ministério da Saúde; 2003. [acesso em 2018 jan. 8]. Disponível em: http://bvsms.saude. gov.br/bvs/publicacoes/politica_nac_urgencias.pdf

7. Brasil. Ministério da Saúde. Sistema Único de Saúde [Homepage na Internet]. Brasília; 2018 [Acesso em 2018 jan. 8]. Disponível em: http://portalms.saude.gov.br/ sistema-unico-de-saude

8. Brasil. Presidência da República, Casa Civil, Subchefia para Assuntos Jurídicos. Constituição da República Federativa do Brasil de 1988 [Internet]. Brasília; 1988 [acesso em 2018 jan. 8]. Disponível em: http://www.planalto.gov.br/ ccivil 03/constituicao/constituicaocompilado.htm

9. Brasil. Presidência da República, Casa Civil, Subchefia para Assuntos Jurídicos. . Lei no 9.656, de 3 de junho de 1998. Dispõe sobre os planos e seguros privados de assistência a saúde [Internet]. Brasília; 1998 [acesso em 2018 jan. 8]. Disponível em: http://www.planalto.gov.br/Ccivil_03/leis/ L9656compilado.htm

10. Brasil. Agência Nacional de Saúde Suplementar. Resolução Normativa $\mathrm{n}^{\circ}$ 424, 26 de junho de 2017. Dispõe sobre critérios para a realização de junta médica ou odontológica formada para dirimir divergência técnico-assistencial sobre procedimento ou evento em saúde a ser coberto pelas operadoras de planos de assistência à saúde [Internet]. Brasília; 2017 [acesso em 2018 jan. 8]. Disponível em: http://www.ans.gov.br/component/legislacao/?view=legisl acao\&task $=$ TextoLei\&format $=$ raw\&id $=\mathrm{MzQzOQ}==$

11. Brasil. Presidência da República, Casa Civil, Subchefia para Assuntos Jurídicos. Lei n ${ }^{\circ} 13.105$, de 16 de março de 2015. Código de Processo Civil [Internet]. Brasília; 2015 [acesso em 2018 jan. 8]. Disponível em: http://www.planalto.gov. br/ccivil_03/_ato2015-2018/2015/lei/113105.htm

12. Brasil. Supremo Tribunal Federal. Glossário Jurídico [Homepage na Internet]. Brasília; 2018 [acesso em 2018 jan. 8]. Disponível em: http://www.stf.jus.br/portal/glossari $\mathrm{o} /$ ?letra $=$ A\&inicio $=40 \&$ fim $=20$

13. Beveridge R, Clarke B, Janes L, Savage N, Thompson J, Dodd G, et al. Implementation Guidelines for The Canadian Emergency Department. Triage \& Acuity Scale (CTAS). Quebec: Canadian Association of Emergency Physicians (CAEP), the National Emergency Nurses Affiliation of Canada (NENA), and L'association des médecins d'urgence du Québec (AMUQ); 1998.

14. Silva MFN, Oliveira GN, Pergola-Marconato AM, Marconato RS, Bargas EB, Araujo IEM. Assessment and risk classification protocol for patients in emergency units. Rev Latino- Am Enfermagem. 2014; 22(2):218-25. DOI: http://dx.doi.org/10.1590/0104-1169.3172.2405

15. Gilboy N, Travers D, Wuerz R. Re-evaluating triage in the new millennium: a comprehensive look at the need for standardization and quality. J Emerg Nurs. 1999;25(6):46873.

16. Holanda AB. Dicionário Aurélio de língua portuguesa. $5^{\mathrm{a}}$ ed. São Paulo: Positivo Editora; 2014.

17. Romani HM, Sperandio JA, Sperandio JL, Diniz MN, Inácio MAM. Uma visão assistencial da urgência e emergência no sistema de saúde. Revista Bioética. 2009;17(1):41-53.

18. Portal Regional da Biblioteca Virtual em Saúde [Homepage na Internet]. São Paulo; 2018. [acesso em 2018 jan. 8]. Disponível em: http://bvsalud.org/

19. US National Library of Medicine. National Institute of Health. PubMed [Homepage na Internet]. Bethesda; 2018 [acesso em 2018 jan. 8]. Disponível em: https:/www.ncbi. nlm.nih.gov/pubmed/

20. US National Library of Medicine. National Institute of Health. MeSH [Homepage na Internet]. Bethesda; 2018 [acesso em 2018 jan. 8]. Disponível em: https://www.ncbi. nlm.nih.gov/mesh/

21. US National Library of Medicine. National Institute of Health. Databases [Homepage na Internet]. Bethesda; 2018 [acesso em 2018 jan. 8]. Disponível em: https://www.nlm. nih.gov/

22. Centro Latino-Americano e do Caribe de Informação em Ciências da Saúde. BVS. DeCS [Homepage na Internet]. São Paulo; 2018 [acesso em 2018 jan. 8]. Disponível em: http://decs.bvs.br/

23. Centro Latino-Americano e do Caribe de Informação em Ciências da Saúde. BVS. DeCS. Pesquisa sobre: Emergência [Internet]. São Paulo; 2018. [acesso em 2018 jan. 8]. Disponível em: http://decs.bvs.br/cgi-bin/wxis 1660. exe/decsserver/

24. US National Library of Medicine. National Institute of Health. MeSH: emergencies [Internet]. Bethesda; 2018. [acesso em 2018 jan. 8]. Disponível em: https://www.ncbi. nlm.nih.gov/mesh/68004630

25. Buchalla CM, Waldman EA, Laurenti R. A mortalidade por doenças infecciosas no início e no final do século XX no Município de São Paulo. Rev Bras Epidemiol. 2003;6(4):335-44. DOI: http://dx.doi.org/10.1590/S1415790X2003000400008

26. França GV. Tratamento Arbitrário. Portal Médico-Conselho Federal de Medicina [Internet]. Brasília; 2001 [acesso em 2018 jan. 8]. Disponível em: http://www.portalmedico.org. $\mathrm{br} /$ Regional/crmpb/artigos/trat_arbt.htm

27. Weinerman ER, Ratner RS, Robbins A, Lavenhar MA. Yale studies in ambulatory medical care. V. Determinants of use of hospital emergency services. Am J Public Health Nations Health. 1966;56(7):1037-56.

28. Vayda E, Gent M, Hendershot A. Emergency department use at two Hamilton hospitals. Can Med Assoc J. 1975;112(8):961-65.

29. Huddleston SS, Ferguson SG. Emergências clínicas: abordagens, intervenções e auto avaliação. $3^{\text {a }}$ ed. Rio de Janeiro: Guanabara Koogan; 2006.

30. Martinez-Almoyna M, Nitschke CAS. Urgência, Urgência Médica ou Emergência Médica? In: Martinez-Almoyna M, Nitschke CAS, organizadores. Regulação Médica dos Serviços de atendimento médico de urgência - SAMU 
Mena $\mathrm{H}$ et al. Urgência e Emergência: os conceitos frente às normas administrativas e legais e suas implicações.

[Internet]. Florianópolis; 1999 [acesso em 2018 jan. 8]. pp. 2-5. Disponível em: http://files.saudecti.webnode. pt/200000026-16b0c17ab9/manual_de_regulacao_ medica_de_urgencia.pdf

31. Giglio-Jacquemot A. Definições de urgência e emergências: critérios e limitações. In: Urgências e emergências em saúde: perspectivas de profissionais e usuários [Internet]. Rio de Janeiro: Editora Fiocruz; 2005 [acesso em 2018 jan. 8]. Disponível em: http://books.scielo.org/id/zt4fg/pdf/ giglio-9788575413784-02.pdf

32. Durand AC, Gentile S, Devictor B, Palazzolo S, Vignally P, Gerbeaux P, et al. ED patients: how nonurgent are they? Systematic review of the emergency medicine literature. Am J Emerg Med. 2011;29(3):333-45. DOI: http://dx.doi. org/10.1016/j.ajem.2010.01.003

33. Garcia TC, Bernestein AB, Bush MA. Emergency Department Visitors and visits: who used the emergency room in 2007? NCHS Data Brief. [Internet]. 2010 [acesso em 2018 jan. 8]; 38:1-8 Disponível em: https://www.cdc. gov/nchs/data/databriefs/db38.pdf

34. Brasil. Agência Nacional de Saúde Suplementar Acolhimento com classificação de risco [Internet]. Brasília; 2012. [acesso em 2018 jan. 8]. Disponível em: http://www. ans.gov.br/images/stories/prestadores/E-ACE-01.pdf

35. Gilboy N, Tanabe T, Travers D, Rosenau AM. Emergency Severity Index (ESI): A Triage. Tool for Emergency Department Care, Version 4. Implementation Handbook 2012 Edition [Internet]. Rockville: Agency for Healthcare Research and Quality - AHRQ Publication;2011. [acesso em 2018 jan. 8]. Disponível em: https://www.ahrq.gov/ sites/default/files/wysiwyg/professionals/systems/hospital/ esi/esihandbk.pdf

36. Organização Panamericana de Saúde. Manual para la implementación de un sistema de triaje para los cuartos de urgencias [Internet]. Washington: OPS; 2011 [acesso em 2018 jan. 8]. Disponível em: http://www1.paho.org/ hq/dmdocuments/2011/HSS_IS_Manual_Sistema_Tiraje_ CuartosUrgencias2011.pdf

37. Australasian College for emergency medicine. Policy on the Australasian triage scale. P06. Version 4 [Internet]. Victoria (Australia); 2013 [acesso em 2018 jan. 8]. Disponível em: https://acem.org.au/getattachment/693998d7-94be-4ca7a0e7-3d74cc9b733f/Policy-on-the-Australasian-TriageScale.aspx

38. Bullard MJ, Unger B, Spence J, Grafstein E, CTAS National Working Group. Revisions to the Canadian emergency department triage and acuity scale (CTAS) adult guidelines. CJEM. 2008;10(2):136-51.

39. Warren DW, Jarvis A, LeBlanc L, Gravel J, CTAS National Working Group, Canadian Association of Emergency Physicians; et al. Revisions to the Canadian triage and acuity scale paediatric guidelines (PaedCTAS). CJEM. 2008;10(3):224-43.

40. Mackway-Jones K, Marsden J, Windle J. Emergency Triage. Manchester Triage Group. $2^{\text {nd }}$ ed. Harayana, India: Blackwell Publishing, 2006

41. Andrade SF. Simulação baseada em agentes para alocação de pessoal em procedimento de classificação de risco na emergência de um hospital. [Tese]. Rio de Janeiro: UFRJ/ COPPE; 2010.

42. Conselho Regional de Medicina do Estado de Goiás
(CREMEGO). Parecer Consulta $n^{\circ}$ 6/2017. A definição de urgência e emergência encontra-se sob a égide da Resolução CFM n ${ }^{\circ}$ 1.451/95 e a eletividade e definida por exclusão [Internet]. Goiânia; 2017 [acesso em 2018 jan. 8]. Disponível em: https://sistemas.cfm.org.br/normas/ visualizar/pareceres/GO/2017/5

43. Conselho Federal de Medicina (CFM). Resolução n 2.079/2014. Dispõe sobre a normatização do funcionamento das Unidades de Pronto Atendimento (UPAs) $24 \mathrm{~h}$ e congêneres, bem como do dimensionamento da equipe médica e do sistema de trabalho nessas unidades [Internet]. Brasília; 2014 [acesso em 2018 jan. 8]. Disponível em: https://sistemas.cfm.org.br/normas/visualizar/resolucoes/ BR/2014/2079

44. Conselho Federal de Medicina (CFM). Resolução $\mathrm{n}^{\circ}$ 2.077/2014. Dispõe sobre a normatização do funcionamento dos Serviços Hospitalares de Urgência e Emergência, bem como do dimensionamento da equipe médica e do sistema de trabalho [Internet]. Brasília; 2014 [acesso em 2018 jan. 8]. Disponível em: https://sistemas.cfm.org.br/ normas/visualizar/resolucoes/BR/2014/2077

45. Conselho Regional de Medicina do Estado da Bahia (CREMEB). Parecer CREMEB 40/08. As situações de urgência/emergência são prioridade absoluta no atendimento a pacientes pelos profissionais de saúde que caso não o façam poderá ser caracterizada a omissão de socorro [Internet]. Salvador; 2008 [acesso em 2018 jan. 8]. Disponível em: https://sistemas.cfm.org.br/normas/ visualizar/pareceres/BA/2008/40

46. Conselho Regional de Medicina do Estado da Bahia (CREMEB). Parecer CREMEB 37/08. Cabe ao cirurgião definir quando as cirurgias são urgências, emergências ou eletivas. A cirurgia para captação de órgãos para transplante embora não se caracterize como urgência ou emergência, não deve ser postergada injustificadamente [Internet]. Salvador; 2008 [acesso em 2018 jan. 8]. Disponível em: https://sistemas.cfm.org.br/normas/visualizar/pareceres/ BA/2008/37

47. Brasil. Presidência da República, Casa Civil, Subchefia para Assuntos Jurídicos. Decreto-lei $\mathrm{n}^{\circ} 2.848$, de 7 de dezembro de 1940. Código Penal [Internet]. Rio de Janeiro; 1940 [acesso em 2018 jan. 8]. Disponível em: http://www. planalto.gov.br/ccivil_03/decreto-lei/Del2848compilado. htm

48. Brasil. Agência Nacional de Saúde Suplementar. Anexo da IN/DIDES $n^{\circ}$ 44. Terminologia Unificada da Saúde Suplementar - Procedimentos Médicos [Internet]. Brasília; 2011[acesso em 2018 jan. 8]. Disponível em: http://www. ans.gov.br/images/stories/Legislacao/in/anexo_in44_dides. pdf

49. São Paulo. Justiça Estadual. Processo no 1010752 41.2015.8.26.0114. 5 ${ }^{\text {a }}$ Vara Cível - Foro Campinas. Juiz: Luiz Cassiolato. Julgado em: 23/03/2017.

50. Brasil. Câmara dos Deputados. Senado Federal. Projeto de Lei $n^{\circ} 4.425 / 1994$. Proíbe a exclusão de cobertura de despesas com tratamento de determinadas doenças em contratos que asseguram atendimento médico-hospitalar pelas empresas privadas de seguro-saúde ou assemelhados [Internet]. Brasília; 1994[acesso em 2018 jan. 8]. Disponível em: http://www.camara.gov.br/proposicoesWeb/fichadetra mitacao?idProposicao $=221429$ 
51. Brasil. Diário da Câmara dos Deputados. Plenário da aprovação do Projeto de Lei ${ }^{\circ} 4.425$, em 15 de outubro de 1997 [Internet]. pp. 32681-32762. Brasília; 1997. [acesso em 2018 jan. 8]. Disponível em: http://imagem.camara.gov. br/Imagem/d/pdf/DCD16OUT1997.pdf\#page $=125$

52. São Paulo. Tribunal de Justiça do Estado de São Paulo. Consulta Completa [Homepage na Internet]. São Paulo; 2018 [acesso em 2018 jan. 8]. Disponível em: esaj.tjsp.jus. br/cjsg/consultaCompleta.do

53. São Paulo. Tribunal de Justiça do Estado de São Paulo. Apelação $\mathrm{n}^{\circ}$ 1001481-32.2016.8.26.0127. Relator: Des. Costa Netto. 9a Câmara de Direito Privado. Julgado em: 27/06/2017.

54. São Paulo. Tribunal de Justiça do Estado de São Paulo. Apelação $n^{0}$ 1001218-42.2016. 8.26.0404. Relator: Des. Luis Mario Galbetti. $7^{\text {a }}$ Câmara de Direito Privado. Julgado em: 23/01/2018.

55. São Paulo. Justiça Estadual. Primeira Vara. Foro de Orlândia. Processo $n^{\circ}$ 1001218-42.2016.8.26.0404. Juiz: Iuri Sverzut Bellesini. Julgado em: 14/11/2016.

56. Brasil. Agência Nacional de Saúde Suplementar. Resolução do Conselho de Saúde Suplementar - Consu no 13, de 3 de novembro de 1998. Dispõe sobre a cobertura do atendimento nos casos de urgência e emergência [Internet]. Brasília; 1998 [acesso em 2018 jan. 8]. Disponível em: http://www. ans.gov.br/component/legislacao/?view=legislacao\&task= TextoLei\&format=raw\&id=MzAw

57. São Paulo. Poder Judiciário. Tribunal de Justiça do Estado de São Paulo. Súmulas do Tribunal de Justiça do Estado de São Paulo aplicadas ao Direito Privado [Internet].. São Paulo; 2013 [acesso em 2018 jan. 8]. Disponível em: http:// www.tjsp.jus.br/Download/SecaoDireitoPrivado/Sumulas. pdf

58. São Paulo. Justiça Estadual. $1^{\text {a }}$ Vara Cível - Foro Regional III - Jabaquara. Processo no 0022453-97.2011.8.26.0003.
Juiz: Março Aurélio Pelegrini de Oliveira. Julgado em: $11 / 04 / 2012$

59. São Paulo. Tribunal de Justiça do Estado de São Paulo. Apelação $\mathrm{n}^{\circ}$ 0022453-97.2011.8.26.0003; Relator: Des. Beretta da Silveira; Órgão Julgador: $3^{\text {a }}$ Câmara de Direito Privado; Julgado em: 29/01/2013.

60. São Paulo. Tribunal de Justiça do Estado de São Paulo. Apelação $n^{\circ}$ 1017992-83.2016.8.26.0005. 5 $5^{\text {a }}$ Câmara de Direito Privado. Relator: Des. Fábio Podestá. Julgado em: 11/10/17.

61. Brasil. Agência Nacional de Saúde Suplementar. Resolução Normativa $\mathrm{n}^{\circ} 259,17$ de junho de 2011. Dispõe sobre a garantia de atendimento dos beneficiários de plano privado de assistência à saúde e altera a Instrução Normativa - IN $\mathrm{n}^{\circ} 23$, de $1^{\circ}$ de dezembro de 2009 , da Diretoria de Normas e Habilitação dos Produtos - DIPRO [Internet]. Brasília; 2009 [acesso em 2018 jan. 8]. Disponível em: http://www. ans.gov.br/component/legislacao/?view=legislacao\&task= TextoLei\&format $=$ raw\&id $=$ MTc1OA==

62. São Paulo. Tribunal de Justiça do Estado de São Paulo. Apelação $n^{\circ}$ 1012610-86.2014.8.26.0100; Relator: Des. Costa Netto. $9^{\text {a }}$ Câmara de Direito Privado; Julgado em: 30/08/2016.

63. Ceará. Poder Judiciário. Tribunal de Justiça do Estado do Ceará. Súmulas [Homepage na Internet]. Cambeba; 2017 [acesso em 2018 jan. 8]. Disponível em: http://www.tjce. jus.br/institucional/consultas-sumulas

64. Rio De Janeiro. Tribunal de Justiça do Estado do Rio de Janeiro. Súmula da jurisprudência predominante do Tribunal de Justiça do Estado do Rio de Janeiro. Rio de Janeiro; 2017 [acesso em 2018 jan. 8]. Disponível em: http://portaltj. tjrj. jus.br/documents/10136/18187/sumulas.pdf?=v03

65. Pernambuco. Tribunal de Justiça de Pernambuco. Súmulas [Homepage na Internet]. Recife; 2017. [Acesso em 2018 jan. 8]. Disponível em: http://www.tjpe.jus.br/sumulas 